\title{
Challenges to Interprofessional Education: will e-Learning be the Magical Stick?
}

This article was published in the following Dove Press journal:

Advances in Medical Education and Practice

\author{
Adel Abdelaziz (D) \\ Tayseer Mansour (D) \\ Rania Alkhadragy (iD) \\ Asmaa Abdel Nasser (iD) 1,2 \\ Memoona Hasnain ${ }^{3}$ \\ 'Medical Education Department, Faculty \\ of Medicine, Suez Canal University, \\ Ismailia, Egypt; ${ }^{2}$ Medical Education Unit, \\ Ibn Sina National College, Jeddah, Saudi \\ Arabia; ${ }^{3}$ Department of Family Medicine, \\ College of Medicine, University of Illinois \\ at Chicago, Chicago, IL, USA
}

Purpose: In Egypt, the main challenges to interprofessional education (IPE) implementation are complexity of the required curricular design, the attitudinal barriers between professions, and the needed resources. Action research work was planned and implemented to identify alternative solutions to overcome barriers to IPE in the local Egyptian context.

Methods: -An 8-week e-learning elective course was developed, implemented, and evaluated. A mixed group of 30 nursing and medical students was enrolled voluntarily in the course. Female to male ratio was 3:2. Four faculty members were assigned to manage the course. Based on the EMRO-WHO guidelines, ethics content was selected and organized. A closed Facebook group was created and utilized as the e-learning platform. Facilitated largegroup and case-based discussions were the main instructional methods. Scoring of mixed small group assignments was the main assessment tool. Course evaluation was conducted using the Interprofessional Socialization and Valuing Scale (ISVS) and an Online-Course Evaluation Questionnaire (OCEQ).

Results: ISVS results revealed that students' perception of ability, comfort and value in working with others, were all positive. The OCEQ provided additional evidence regarding the satisfaction of students with the Facebook group as a learning platform. Assignment submission rate was $90 \%$. Success rate of small group assignments (scores $\geq 60 \%$ ) was $100 \%$. Response rate to the open online discussions was $63 \%$. Through peer evaluation as well as direct observation of online discussions, there was evidence of distinct contributions by females and by medical students compared to nursing students.

Conclusion: As evidenced by the students' perception and performance, our IPE distance learning experience was valuable. Motivation of medical students as well as females was evident. IPE is a challenging process. The elective approach and using DL can offer solutions. Conducting relevant practical sessions as well as sustainability of this IPE e-learning experience remain key challenges.

Keywords: adult learning, distance education and online learning, cooperative/collaborative learning, teaching/learning strategies

\section{Introduction}

Interprofessional education (IPE) is an important and widely used pedagogical approach for preparing students of different health professions to provide collaborative and quality patient care. The idea behind using IPE is that once health care professionals study together they can work together in a cooperative manner with the common goal of providing quality health care to their patients. ${ }^{1}$

IPE used to be simply defined as "learning together in order to practice together". ${ }^{2}$ Nowadays, the definition of the Centre for the Advancement of Interprofessional Education (CAIPE) is being more widely accepted. This definition
Correspondence: Rania Alkhadragy

Medical Education Department, Faculty of

Medicine, Suez Canal University, Round

Road 4I I I, Imailia, Egypt

Tel +20 1005107568

Email drraniamed@gmail.com
Advances in Medical Education and Practice 2021:12 329-336

mit your manuscript in $\mathbf{P}$ 
indicates that IPE occurs when two or more professions learn with each other in order to establish collaborative and quality care. It includes all learning opportunities in academic or workplace-based settings, before or after qualification. $^{3}$ IPE occurs when health professionals are educated together in multiprofessional or mixed educational settings. Accordingly, they will learn to work as a team while they are studying. The end result will be effective and efficient health care provision. ${ }^{4,5}$

IPE implementation can lead to benefits for health care users, students, and professionals. Concerning health care, IPE guards against occurrence of communication failures and "unhelpful protectionism". For health professions education institutions, IPE can help in the development of the skills needed to operate successfully in teams toward achievement of the institutional goals. Meanwhile, IPE experiences can help students to come across work difficulties and barriers of real life settings. ${ }^{6}$

When trying to refer to theoretical background for IPE, systematic reviews highlighted that few studies directly focused on a particular theoretical framework. ${ }^{7}$ Therefore; the combination of the following teaching methods was suggested when applying IPE courses: exchange-based learning in the form of debates and case studies; action-based learning using problem-based cases; observation-based learning, eg, joint visits to a patient by students from different professions; simulation-based learning, using role-play; practice-based, eg, co-location across professions for placements, E-learning and blended learning, all together with the didactic lectures. ${ }^{8}$

Despite the well-known benefits of IPE, there is evidence of a set of barriers or challenges that jeopardize the implementation of this approach in health professions education. These challenges can be categorized under the following categories: professional boundaries, curriculum, resources, leadership, stereotypes and attitudes, teaching, variety of students, different IPE concepts, enthusiasm, and requirements of accreditation. ${ }^{3}$

In Egypt, as well as in other countries in the region, IPE faces challenges that have guarded against the general implementation of this teaching approach. Examples are: complexity of curriculum design needed for IPE as well as the attitudinal barriers and distinct identities between professions. $^{4}$ Throughout this study, an action research work was planned and implemented to identify alternative solutions to overcome barriers to IPE in the local Egyptian context. E-learning was applied in this study, and is highly encouraged by health professions institutions, especially after COVID 19 situation.

\section{Materials and Methods Course Design}

A distance learning (DL) 8-week course was designed and implemented on elective basis. Kern et al (2015) Six-Step Approach for curriculum development was followed to guide the process of course design. ${ }^{9}$

The course was introduced for study as a summer course. A mixed group of 30 nursing and medical students were enrolled voluntarily in the course. Female to male ratio was 3:2. Four faculty members were assigned to manage design, implementation and evaluation of the course and worked voluntarily as well. Based on the Eastern Mediterranean Regional Office (EMRO-WHO) guidelines, ethics content was selected and organized over the schedule of 8 weeks. ${ }^{10}$ A closed Facebook group was created and utilized as the e-learning platform. Selection of the Facebook interface was based on exploring the views of the targeted group of students regarding utility, feasibility and acceptability of this medium.

\section{Implementation}

Teaching of the content was based on two main instructional methods. The first was by facilitated large-group discussions based on case scenarios. The other method of instruction was a small group discussion of another set of case scenarios addressing complex ethical dilemmas. An example of a case scenario is presented, with questions directed to students stimulating discussion, in Box 1. There were 6 students in each group, nursing and medical students divided equally. Each small group was required to submit a report that includes a solution for the ethical dilemmas. Scoring of these assignments as well as the substantial contributions in the large group discussions were the main assessment tools. Self and peer evaluation with feedback were utilized.

Monitoring and facilitation of the ongoing discussions and giving timely feedback and comments were conducted by the four faculty members around the clock.

To ensure motivation of students, financial rewards in the form of incentives as well as selection of the best performing group and appraising their performance through relevant scholarship activities associated with 
Box I Case Scenario with Proposed Questions

Case scenario (for small group assignment)

Time: Up to the midnight of .....

$\mathrm{Nada}$ a fourth-year student who is doing her obstetrics and gynecology rotation, is spending a day in a university obstetrics clinic. After she has seen several patients and observed a couple of procedures, the attending physician, Dr. Omnia, hands Nada a chart filled with background information and a hand-out listing the information she will need to gather and instructs her, "Nada, please go learn this patient's story and see what kinds of questions she has about the procedure."

The first thing Nada notices when she opens the chart are the words "trisomy 21 ". She knows well what this means - in addition to her medical training, she has an adult brother with Down syndrome. As she continues to read, she learns that the woman, Fouzia, is 33 years old and is II weeks pregnant. Fouzia has had a long battle with infertility because she has mosaic Turner's syndrome. She has had seven miscarriages but has a one-year-old son at home.

At eight weeks gestation, Fouzia had an abdominal ultrasound that showed thickening of the nuchal fold. She subsequently had cell-free fetal DNA testing which indicated she had a high chance of having a child with Down syndrome. Nada wonders what kind of counseling Fouzia received prior to arriving in the obstetric clinic, particularly since she has not had a true diagnostic test for Down syndrome, such as a chorionic villus sample, and there were no notes in her health record from any genetic counseling sessions.

Nada takes a deep breath and knocks on the patient's door. Inside the room, she finds a teary-eyed woman, sitting and holding hands with her husband. When Nada asks Fouzia about her story, she explains, "We were so happy to be pregnant again after having so many miscarriages. It was devastating to learn about the Down syndrome. We just...can't imagine putting that kind of burden on our family."

Nada responds, "I'm sorry to hear that you've been through so much. I hope that we can provide the support you need." She goes on, "Do you feel as though you have received adequate information about Down syndrome?" Fouzia nods, tears streaming down her cheeks; her husband stares at the floor.

Fouzia seems to regard the cell-free DNA test as diagnostic of Down syndrome; this worries Nada, particularly since it seems that she has not received any counseling. She's also concerned that Fouzia's and her husband's decision to abort might not be an informed one. Nada feels some obligation to speak up on behalf of the often-underestimated and undervalued population of people with Down syndrome. She wonders whether to speak to Dr. Omnia and to Fouzia and her husband about her concerns, and she wonders what to say.

In no more than 400 words

- Discuss all the potential options for deciding about this pregnancy.

- Explain the role of autonomy, consenting, unbiased information in decision making regarding this pregnancy.

- What is the proper final decision that should be taken in this case? Based on what?

paper were announced. All these act as effective external motivators.

\section{Course Evaluation}

Course evaluation was conducted by two means. First was through using the Interprofessional Socialization and Valuing Scale (ISVS) to evaluate the students' attitudinal changes as a result of their involvement in the interprofessional learning process. Second was the Online-Course Evaluation Questionnaire (OCEQ) to evaluate the students' perceptions related to the utilized online interface.

\section{The Interprofessional Socialization and Valuing Scale (ISVS)}

The ISVS is a measure to assess levels of interprofessional socialization in both students and practitioners. Also, this measure can relate this interprofessional socialization to some other constructs like interprofessional collaboration and identity that can be developed as result of engagement in an IPE experience. ${ }^{11}$

\section{The Online Course Evaluation Questionnaire (OCEQ)}

To be context-specific for online learning, the OCEQ was adapted from the Student Course Experience Questionnaire (SCEQ). The OCEQ consists of 7 scales to evaluate effectiveness of teaching, learning materials and activities, goals and standards, volume of work, appropriateness of assessment, engagement with the topic, and quality of blended learning. ${ }^{12}$

\section{Ethical Considerations}

Prior to starting the study, ethical approval had been obtained from Suez Canal University Ethics committee. Written informed consent had been given by study participants and the guidelines outlined in the Declaration of Helsinki were also followed. ${ }^{13}$

Enrollment in the course was managed on elective basis. Informed consent was taken from each student.

Students were informed that they had the freedom to withdraw themselves from the course at any time, also, they had been informed that their evaluation results as well 
as their thoughts and ideas will remain confidential and not be disclosed under any circumstances.

\section{Results}

Results of our experience in the development, implementation, and evaluation of the distance learning IPE ethics course were classified as follows: first are the elements of the designed course like goals, objectives, instructional strategies, and assessment tools (Box 2).

\section{Students' Assessment}

Study of the course was based on 8 themes. A group of case scenarios, each addressing an ethical dilemma, was developed and introduced for online discussion by the large group of students enrolled in the course. The response rate of students to the cased-based discussions was $63 \%$ (100\% equals at least a substantial contribution of each student $\times 8$ case-based discussions $\times 30$ students $=240$ contributions). Through direct observation of online discussions, there was evidence of distinct contributions by female students compared to male students and by medical students compared to nursing students (Table 1).

Ninety percent of the required assignments (18 out of 20 ) were submitted. Around $95 \%$ of the submitted assignments received more than the pass mark (6/10), around quarter of these assignments had full marks (Table 2).

The ISVS questionnaire is composed of three scales which are: a) self-perceived ability to work with others, b) value in working with others, and c) comfort in working with others. The mean item scores as shown in Table 3 indicate that three constructs measured by the tool were positively perceived as a consequence of participation in the course.

Open-ended questions where included in a separate section and were then analyzed qualitatively to identify students' perception of challenges encountered during their study in the course.

There, the OCEQ provided additional evidence regarding the satisfaction of students with the Facebook group as

Box 2 Course Objectives and Learning Outcomes.

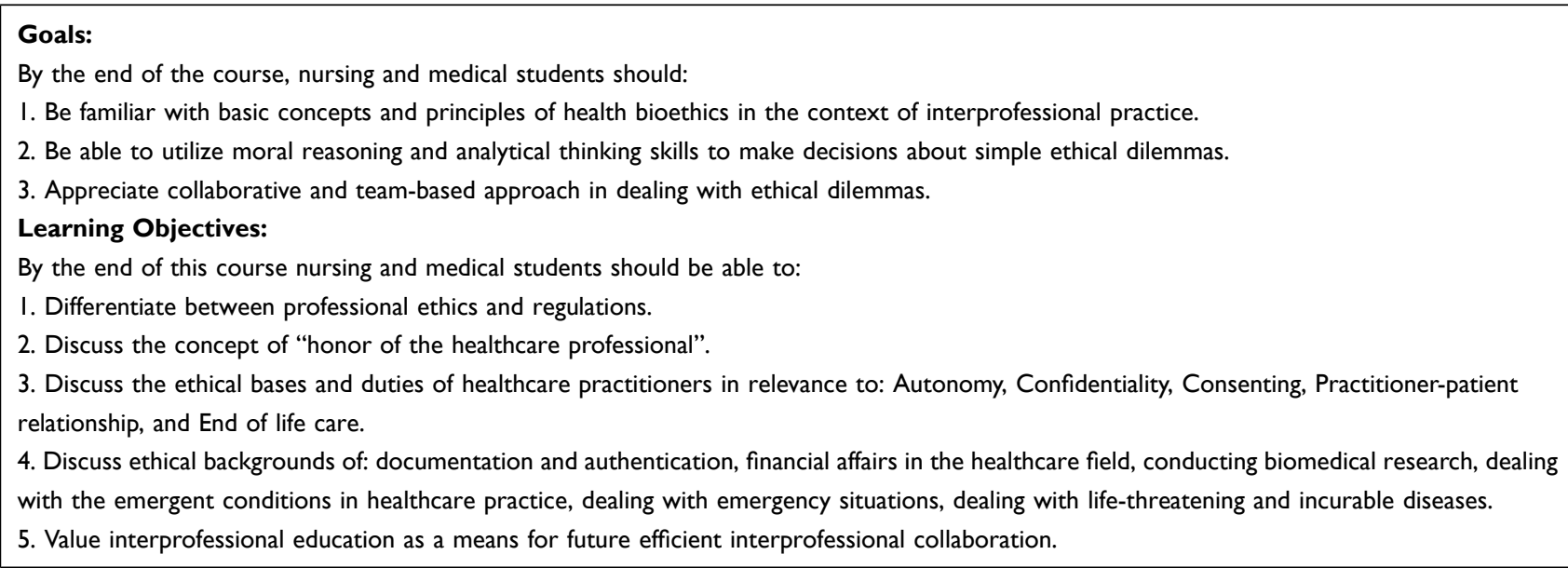

Note: Data from Cheftel. ${ }^{18}$

Table I Collective Score of Group Members in the Large Group Discussions

\begin{tabular}{|l|c|c|c|c|c|c|c|c|c|}
\hline & Case I & Case 2 & Case 3 & Case 4 & Case 5 & Case 6 & Case 7 & Case 8 & Total \\
\hline & 10 & 10 & 10 & 10 & 10 & 10 & 10 & 10 & 80 \\
Group A & 2.2 & 2.7 & 3.3 & 1.7 & 3.4 & 2 & 2.7 & 2 & 20 \\
Group B & 2.5 & 2 & 3.3 & 0.5 & 2 & 2 & 3.3 & 2 & 17.6 \\
Group C & 2 & 0.5 & 2.7 & 1.5 & 2 & 3 & 2.8 & 3.8 & 18.3 \\
Group D & 3.5 & 3.7 & 5.5 & 6 & 5 & 4.7 & 4.3 & 5.2 & 40 \\
Group E & 4.3 & 5.7 & 5.3 & 4.8 & 5.5 & 6.3 & 5.3 & 5.3 & 42.5 \\
\hline
\end{tabular}


Table 2 Small Group Assignments

\begin{tabular}{|l|c|c|c|c|c|}
\hline & Assignment I & Assignment 2 & Assignment 3 & Assignment 4 & Total \\
\hline & 10 & 10 & 10 & 10 & 40 \\
Group A & 7.5 & 8 & 7.5 & - & 24 \\
Group B & 8 & 8.5 & 5 & - & 21.5 \\
Group C & 7 & 10 & 9 & 6 & 32 \\
Group D & 8.5 & 9 & 9 & 9.5 & 36.5 \\
Group E & 8.5 & 10 & 8 & 36 \\
\hline
\end{tabular}

Table 3 Means and Standard Deviation of the Three Scales of ISVS Questionnaire (Scales Were Rated Out of 7)

\begin{tabular}{|l|l|l|l|}
\hline Scales & $\begin{array}{l}\text { Number } \\
\text { of Items }\end{array}$ & Mean & $\begin{array}{l}\text { Standard } \\
\text { Deviation }\end{array}$ \\
\hline $\begin{array}{l}\text { Self-Perceived Ability to } \\
\text { Work with Others }\end{array}$ & 9 & 5.81 & 0.78 \\
\hline $\begin{array}{l}\text { Value in Working with } \\
\text { Others }\end{array}$ & 9 & 5.52 & 1.2 \\
\hline $\begin{array}{l}\text { Comfort in Working with } \\
\text { Others }\end{array}$ & 6 & 5.32 & 0.79 \\
\hline
\end{tabular}

a learning platform. Overall satisfaction of the students with their first online experience was evident (Main=4.3 $(\mathrm{SD}=1.1)$ ) (Table 4).

Regarding gender variation, male to female ratio of main satisfaction was 1:1. Significant difference in satisfaction between medical and nursing students was in favor of the nursing students (Medicine $=3.7$ and Nursing $=4.9$ ).

Table 4 Students' Satisfaction with the Online Experience as Well as Their Gender and Affiliation Differences (Overall Satisfaction Was Rated Out of 5)

\begin{tabular}{|c|c|c|c|}
\hline & Mean (SD) & $t$-Test & Significance \\
\hline \multicolumn{4}{|c|}{ Overall satisfaction of students with the online course } \\
\hline - Overall course satisfaction & $4.2(0.83)$ & NA & NA \\
\hline \multicolumn{4}{|c|}{ Satisfaction of the two genders with the online course } \\
\hline - Male & $4.3(1.11)$ & \multirow[t]{2}{*}{0.0} & \multirow[t]{2}{*}{1.00} \\
\hline - Female & $4.3(0.76)$ & & \\
\hline \multicolumn{4}{|c|}{$\begin{array}{l}\text { Satisfaction of students from the two programs with the online } \\
\text { course }\end{array}$} \\
\hline - Medicine & $3.7(0.95)$ & \multirow[t]{2}{*}{-2.8} & \multirow[t]{2}{*}{$0.03 *$} \\
\hline - Nursing & $4.9(0.38)$ & & \\
\hline
\end{tabular}

Note: *Significant.
A set of the challenges has been identified through this experience by the students and their faculty staff members (Box 3).

These challenges were identified by means of qualitative analysis of the students' responses to the open-ended questions included in the different tools for evaluation or by direct feedback from faculty and course coordinators.

\section{Discussion}

There are three main pillars of this action research work. The three pillars in order of research priority are: IPE, DL, and Ethics. During the phases of development, implementation and evaluation, emphasis paid to each of the three pillars was proportionate to its research priority.

During implementation, there were multiple obtained inferences on the enthusiasm and motivation of the medical and nursing students enrolled in the course. Examples of these inferences include the high level of attendance (either face-to-face or online), active participation in online discussions, and the assignment submission rate. Only "logging in" to the course through the online interface was not counted as attendance. ${ }^{14,15}$

Studies have reported key factors for improving working practice among them: learners' motivation, satisfaction, expectation, training and support among. ${ }^{16,17}$

\section{Course Design}

The development of the IPE online course was a rich experience. As the course was conducted collaboratively among experts in the three fields of IPE, DL, and Health Bioethics, this led to more interaction between the three fields as well as exchange of thoughts, ideas, and experience. Experts' opinions have enhanced the final implemented version.

The course document including its plan for implementation was benchmarked to the United Nations Educational, Scientific and Cultural Organization 
Box 3 Challenges Identified by the Students, Faculty, and Course Coordinators

I. Distinct identity between nursing and medical students

2. Lack of resources for implementation of IPE. These are mainly:

- Trained and motivated faculty members, and

- Time in already crowded medical or nursing curricula.

3. The inability to conduct relevant hands-on sessions through the online teaching.

4. The difficulty in maintaining equal opportunities of interaction for the nursing and medical students.

5. Making the IPE e-learning experience sustainable.

(UNISCO) bioethics core curriculum. ${ }^{10,18}$ Benchmarking was conducted by two Health Professions Education experts who have special expertise in the fields of health ethics as well as distance e-learning. Feedback by the reviewers included recommendations to reduce the content, re-distribute themes of the different weeks as well as having student assessment group assessment rather than individual student assessment. This was in line with theoretical analyses stressing active participation and collaboration among students in promoting the effectiveness of online learning. As in the majority of online courses, still traditional tutor individualized is the primary means for assessing student performance, and collaborative learning is marginalized and not the core focus..$^{19,20}$

Plans for students' assessment and program evaluation were agreed upon accordingly.

\section{Students' Assessment}

Students' assessment in the IPE course was conducted through evaluation and scoring of the submitted group assignments as well as individual student participation in discussions. According to Kearn (2012), ${ }^{21}$ written assignments and online discussion are the main categories of student assessment in e-learning courses. Student groups submitted $90 \%$ of the required assignments. All the submitted assignments $(100 \%)$ exceeded the pass mark (score $\geq 6 / 10$ ). Response rate to the open online discussions was $63 \%$. Online courses may be labeled as artificial, however, acceptable levels of satisfaction have been reported with emphasis on the importance of interaction in virtual learning settings. ${ }^{20,22}$

Moreover, positive correlations between overall interaction and student satisfaction were noted; as interaction levels went up, satisfaction and learning scores tended to go up as well. ${ }^{22}$ Through peer evaluation as well as direct observation of online discussions, there was evidence of distinct contributions by female students compared to male students and by medical students compared to nursing students. ${ }^{8,20}$

\section{Course Evaluation}

Based on the component analysis of the ISVS, the tool is composed of three subscales which are: a) Self-Perceived Ability to Work with Others, b) Value in Working with Others, and c) Comfort in Working with Others.

The mean item scores of the three different subscales revealed the following: 5.32 for Comfort in Working with others, 5.52 for Value in Working with Others, and 5.81 for Self-Perceived Ability to Work with Others. These inferences indicate that self-perceived ability to work with others occurred to a great extent as a consequence of participation in this course. As indicated by results of the ISVS, students' perception of ability, comfort and value in working with others, were all positive. These are similar to the results of Brown et al (2016) who demonstrated an effectiveness and feasibility of their adopted IPE course. ${ }^{23}$

The OCEQ provided additional evidence regarding the satisfaction of students with the Facebook group utilized as the learning platform. Main overall satisfaction of the students with their first online experience was 4.3 $(\mathrm{SD}=1.1)$. Male to female ratio related to their satisfaction with course was 1:1. Significant difference in the course satisfaction was evident between medical and nursing students where nursing students looked more satisfied with the course (mean satisfaction of nursing students $=4.9$, while medical students $=3.7$ ). Meanwhile, similar studies using OCEQ reported students' satisfaction with the overall learning experience and linked that to staff interaction in course delivery. ${ }^{24}$

\section{Challenges}

The main challenges to this IPE experience included: belonging to a group and distinct identity formation, lack of resources particularly trained and motivated faculty members, and shortage of time in an already crowded curricula. These challenges to IPE can be overcome through utilization of e-learning, redistribution of available 
human and financial resources, introducing relevant courses on elective basis, and seeking assistance from volunteer and interested faculty members. Most of these challenges are consistent with those defined by Anderson (2017), who considered that these challenges interfere with implementation of IPE. ${ }^{25}$

Challenges of using the online teaching experience included the inability to conduct relevant practical and hands-on sessions, also the difficulty in maintaining equal opportunities for contribution and active participation between students of different backgrounds. Similar challenges were identified by both Wang (2006) and Mishra and Bartram (2002). As indicated by these two publications using animation, blended learning, and flipped classrooms can overcome these to challenges. $^{26,27}$

Sustainability or at least reproducibility of this IPE e-learning experience remains the most important main challenge. It indicates political will and support at the higher university and ministerial levels.

Still, there are limitations of this study such as lack of control group, dependence on volunteering students and staff, the sustainability and generalizability of results.

Future research is needed to explore how to increase sustainability and students' internal motivation in the same contexts.

\section{Conclusion}

The IPE online course on health bioethics was a valuable experience to overcome the barriers to implementation of IPE on a wider scale in the local Egyptian context. As evidenced by the students' perception and performance, our IPE distance learning experience was valuable. Motivations of medical students as well as females were evident. IPE is a challenging process. The elective approach and using DL can offer solutions. Conducting relevant practical sessions as well as sustainability of this IPE e-learning experience remain key challenges.

\section{Abbreviations}

DL, distance learning; EMRO, Eastern Mediterranean Regional Office; ISVS, Interprofessional Socialization and Valuing Scale; OCEQ, Online-Course Evaluation Questionnaire; IPE, inter professional education; UNISCO, United Nations Educational, Scientific and Cultural Organization; WHO, World Health Organization.

\section{Acknowledgments}

Special thanks go to Suez Canal University stakeholders at the Faculty of Medicine and Faculty of Nursing and students who participated in this course.

\section{Disclosure}

The authors report no conflicts of interest in this work.

\section{References}

1. Buring SM, Bhushan A, Broeseker A, et al. Interprofessional education: definitions, student competencies, and guidelines for implementation. Am J Pharm Educ. 2009;73(4):59. doi:10.5688/aj730459

2. Hammick M. Interprofessional education: concept, theory and application. J Interprof Care. 1998;12(3):323-332. doi:10.3109/135618 29809014123

3. Sunguya BF, Hinthong W, Jimba M, Yasuoka J, Zunt JR. Interprofessional education for whom?-challenges and lessons learned from its implementation in developed countries and their application to developing countries: a systematic review. PLoS One. 2014;9(5):e96724. doi:10.1371/journal.pone.0096724

4. Hosny S, Kamel MH, El-Wazir Y, Gilbert J. Integrating interprofessional education in community-based learning activities: case study. Med Teach. 2013;35(sup1):S68-S73. doi:10.3109/0142159X.2013. 765550

5. World Health Organization. Learning Together to Work Together for Health. Report of a WHO Study Group on Multiprofessional Education of Health Personnel: The Team Approach. World Health Organization; 1988.

6. Illingworth $\mathrm{P}$, Chelvanayagam $\mathrm{S}$. Benefits of interprofessional education in health care. Br J Nurs. 2007;16(2):121-124. doi:10.12968/ bjon.2007.16.2.22773

7. Hean S, Craddock D, Hammick M, Hammick M. Theoretical insights into interprofessional education: AMEE Guide No. 62. Med Teach. 2012;34(2):e78-e101. doi:10.3109/0142159X.2012.650740

8. Guraya SY, Barr H. The effectiveness of interprofessional education in healthcare: a systematic review and meta-analysis. Kaohsiung $J$ Med Sci. 2018;34(3):160-165. doi:10.1016/j.kjms.2017.12.009

9. Sweet LR, Palazzi DL. Application of Kern's Six-step approach to curriculum development by global health residents. Educ Health. 2015;28(2):138. doi:10.4103/1357-6283.170124

10. World Health Organization. Islamic Code of Medical and Health Ethics. World Health Organization; 2005.

11. King G, Orchard C, Khalili H, Avery L. Refinement of the interprofessional socialization and valuing scale (ISVS-21) and development of 9-item equivalent versions. J Contin Educ Health Prof. 2016;36 (3):171-177. doi:10.1097/CEH.0000000000000082

12. Ginns P, Ellis R. Quality in blended learning: exploring the relationships between on-line and face-to-face teaching and learning. Internet High Educ. 2007;10(1):53-64. doi:10.1016/j.iheduc.2006.10.003

13. Aldughaither SK, Almazyiad MA, Alsultan SA, et al. Student perspectives on a course on medical ethics in Saudi Arabia. J Taibah Univ Med Sci. 2012;7(2):113-117. doi:10.1016/j.jtumed.2012.11.002

14. World Medical Association. World Medical Association Declaration of Helsinki. Ethical principles for medical research involving human subjects. Bulletin of the World Health Organization. 2001;79(4):373.

15. Capone R, De Caterina P, Mazza G Blended learning, flipped classroom and virtual environment: challenges and opportunities for the 21st century students. Proceedings of EDULEARN17 conference; Barcelona, Spain; 2017. DOI: 10.21125/edulearn.2017.0985.

16. Swan K, Shen J, Hiltz S. Assessment and collaboration in online learning. J Asynchronous Learn Netw. 2008. 
17. Volery T, Lord D. Critical success factors in online education. Int $J$ Educ Manag. 2000;14(5):216-223.

18. Cheftel J. Bioethics Core Curriculum Section 1: Syllabus Ethics Education Programme. Paris: UNESCO; 2008.

19. Chen YJ, Chen PC. Effects of online interaction on adult students' satisfaction and learning. J Human Resource Adult Learn. 2007;3 (2):78-89.

20. Swan K. Learning online: a review of current research on issues of interface, teaching presence and learner characteristics. Elements Qual Online Educ. 2004;5:63-79.

21. Kearns LR. Student assessment in online learning: challenges and effective practices. J Online Learn Teach. 2012;8(3):198.

22. Silverman H, Strosberg M, Luna F, Philpott S, Hemmerle CA. An analysis of online courses in research ethics in the Fogarty-sponsored bioethics training programs. J Empirical Res Human Res Ethics. 2013;8(5):59-74. doi:10.1525/jer.2013.8.5.59
23. Brown B, Brehm B, Dodge HS, et al. Evaluation of an interprofessional elective course for health professions students: teaching core competencies for interprofessional collaborative practice. Health Interprof Pract. 2016;3(1):4. doi:10.7710/2159-1253.1103

24. Alkhadragy RA, ElAraby SE, Hassan N, Hefny MA, Talaat W. Implementation and evaluation of a blended integrated course in a problem-based learning program. J Educ Soc Behav Sci. 2018;24:120. doi:10.9734/JESBS/2018/38657

25. Anderson E. Interprofessional education and the challenges of moving forward. Med Edu. 2017;51(8):873-874. doi:10.1111/medu. 13270

26. Mishra AK, Bartram J. Skills Development Through Distance Education. Commonwealth of Learning (COL); 2002.

27. Wang S-K. Learning hands-on skills in an online environment: the effectiveness of streaming demonstration animation. $J$ Interact Online Learn. 2006;5(1):1.

\section{Publish your work in this journal}

Advances in Medical Education and Practice is an international, peerreviewed, open access journal that aims to present and publish research on Medical Education covering medical, dental, nursing and allied health care professional education. The journal covers undergraduate education, postgraduate training and continuing medical education including emerging trends and innovative models linking education, research, and health care services. The manuscript management system is completely online and includes a very quick and fair peer-review system. Visit http://www.dovepress.com/testimonials.php to read real quotes from published authors. 